\title{
Assessment of Knowledge of Primary School teachers Regarding Malnutrition Among Children
}

\author{
Ms. Herbaksh Kaur, Ms. Kuldeep Kaur, Ms.Simaranjit Kaur \\ (Assistant Professor, M. M. College of Nursing, Mullana Ambala)
}

\begin{abstract}
Children are the most important segments for a nation for the optimal physical, mental, emotional development of its future worthy citizens. The Present study aimed to assess the knowledge of Primary school teachers regarding malnutrition among children in selected schools of Ambala, Haryana and to determine the association of knowledge of primary school teachers with selected sample characteristics. The research approach was non-experimental with Descriptive Survey Design. The final data was collected in the month of March after getting formal permission from principals of schools of Ambala Haryana. Total enumeration Technique was used for primary school teachers. The data was collected from 50 primary school teachers by structured knowledge questionnaire. The 30 items having minimum rating score of 0 and maximum rating score of 30. Analysis was done in accordance with study. Tool was validated from seven experts and tools were found reliable. Major Findings of the Study revealed that Majority 20 (40\%) of primary school teachers were from the age group 26-30 years , 36(72\%) of primary school teachers were females, 28 (56\%) had completed their education with B.ED ,35 (70\%) were married ,31(62\%) of primary school teachers were had experience less than 5year, 45(90\%) of primary school teachers did not come across child with malnutrition. There is significant association of level of knowledge of primary school teachers with educational status. Maximum $28(56 \%)$ Primary school teachers were having good knowledge regarding malnutrition while $17(34 \%)$ were having average knowledge malnutrition followed by 6(10\%) were in category of very good and no were having below average. Primary school teachers had good knowledge in the area of sign and symptoms of malnutrition(73\%), causes of malnutrition(72\%), introduction and definition of malnutrition(69\%)and treatment of malnutrition(61\%), while average knowledge in prevention of malnutrition(59\%) and risk factors of malnutrition $(51 \%)$.
\end{abstract}

Key Words: Knowledge, Primary school teachers, Malnutrition

\section{Introduction:}

Children are the most important segments for a nation for the optimal physical, mental, emotional

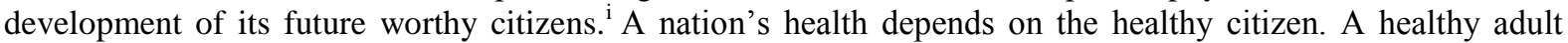
emerges from a healthy child. ${ }^{\text {ii }}$ Good nutrition is the fundamental basic right for the maintenance of positive health ${ }^{\text {iii }}$. A proper diet is essential from early stage of life children below age of five year constitute over $20 \%$ of our population and also form a most vulnerable group. The foundation of good health and sound mind are laid during this period of life ${ }^{\text {iv }}$.

The level of food insecurity within the household determines the nutritional status of children, and is the immediate cause of malnutrition. The caregivers and parents make most food choices for meals consumed at home. These choices are based on culture, beliefs, cost, time restraints and availability.

The nutritional status of a child, as with any individual, is assessed through dietary, anthropometric, biochemical and physical observation for signs of malnutrition. These methods of measurement are usually done in combination for more accurate results. When there is a deficiency in the amount and nutritional value of the food consumed, the growth pattern of a child becomes disrupted owing to nutrient deficiencies. ${ }^{\mathrm{vi}}$

So investigator felt the need to investigate the knowledge of primary school teacher which are more close to students and spend a great deal of time with students and can participate in recognize the early sign and symptoms of malnutrition and can report to their parents soon that the early intervention can be anticipated collaboratively by teacher and parents.

\section{OBJECTIVES:}

1. To assess the knowledge of Primary School teachers regarding malnutrition among children.

2. To determine the association of knowledge of Primary School teachers regarding malnutrition among school going children with selected sample characteristics.

\section{Materials And Methods:}

The research approach adopted for the study was non-experimental with descriptive survey design. 
The present study was conducted on fifty primary school teachers of four schools of Mullana,Ambala,Haryana to assess their knowledge regarding malnutrition among children. In this study, convenience sampling technique was used for schools and total enumeration for primary school teachers.

The tools developed and used for data collection was Structured Knowledge Questionnaire and the technique was paper- pencil method.

Section I: It comprised of items seeking information pertaining to Demographic variables (Age,gender ,educational status, marital status, total years of teaching experience, child with malnutrition in your school.)

Section II: It comprised of 30 multiple objectives type items. These knowledge items are covering the following areas:

- Introduction \& definition

- Causes

- Risk factors

- $\quad$ Sign and symptoms

- Treatment

- Prevention

The maximum possible score on the Structured Knowledge Questionnaire was 30 (reliability was found to be 0.9 by $\mathrm{KR}_{20}$ ). The tool was submitted to the seven experts for validation. Suggestions given by experts were duly made and final draft was prepared.

The data obtained were analyzed using both descriptive and inferential statistics.

\section{RESULTS:}

TABLE 1: Frequency and Percentage Distribution of Sample characteristics

\begin{tabular}{llll}
\multicolumn{1}{c}{ S.NO. } & Sample characteristics & Frequency(f) & Percentage(\%) \\
\hline $\mathbf{1}$ & Age in years & 14 & $20 \%$ \\
$\mathbf{1 . 1}$ & $<25$ years & 20 & $40 \%$ \\
$\mathbf{1 . 2}$ & $26-30$ years & 05 & $10 \%$ \\
$\mathbf{1 . 3}$ & $31-35$ years & 11 & $22 \%$ \\
$\mathbf{1 . 4}$ & $>36$ years & & $28 \%$ \\
$\mathbf{2}$ & Gender & 14 & $72 \%$ \\
$\mathbf{2 . 1}$ & Male & 36 & $12 \%$ \\
$\mathbf{2 . 2}$ & Female & & $56 \%$ \\
$\mathbf{3}$ & Educational status & 06 & $10 \%$ \\
$\mathbf{3 . 1}$ & D.ED & 28 & $12 \%$ \\
$\mathbf{3 . 2}$ & B.ED & 05 & $10 \%$ \\
$\mathbf{3 . 3}$ & Elementary teacher training & & $26 \%$ \\
& Any other(J.B.T) & 06 & $70 \%$ \\
$\mathbf{3 . 4}$ & (B.A) & 05 & $02 \%$ \\
$\mathbf{3 . 5}$ & Marital status & 13 & $02 \%$ \\
$\mathbf{4}$ & Single & 35 & \\
$\mathbf{4 . 1}$ & Married & 01 & $62 \%$ \\
$\mathbf{4 . 2}$ & Divorced/separated & 01 & $30 \%$ \\
$\mathbf{4 . 3}$ & Widow & & $2 \%$ \\
$\mathbf{4 . 3}$ & Total year of teaching experience & 31 & \\
$\mathbf{5}$ & $<5$ years & 15 & $10 \%$ \\
$\mathbf{5 . 1}$ & 6-10 years & 01 & $90 \%$ \\
$\mathbf{5 . 2}$ & 11-15 years & 03 & \\
$\mathbf{5 . 3}$ & $>16$ years & & \\
$\mathbf{5 . 4}$ & & 05 & \\
$\mathbf{6}$ & Have you ever come across child with & 45 & \\
$\mathbf{6 . 1}$ & malnutrition & & \\
$\mathbf{6 . 2}$ & Yes & & \\
\hline
\end{tabular}

TABLE 2: Frequency and percentage distribution of Primary School Teachers in terms of level of knowledge. $\quad \mathrm{N}=50$

\begin{tabular}{|l|c|c|c|}
\hline \multicolumn{1}{|c|}{ LEVEL OF } & RANGE OF SCORE & FREQUENCY & PERCENTAGE \\
\hline VERY GOOD & & 5 & $10 \%$ \\
GOOD & $675 \%$ & 28 & $56 \%$ \\
AVERAGE & $50-65 \%$ & 17 & $34 \%$ \\
BELOW AVERAGE & $<50 \%$ & 0 & $0 \%$ \\
\hline
\end{tabular}

The data in Table 2 revealed that level of knowledge of Primary school teachers in term of very 
$\operatorname{good}(<75 \%)$, Good $(61-75 \%)$, Average $(50-60 \%)$, Below average $(<50 \%)$. Maximum 28(56\%) Primary school teachers were having good knowledge regarding malnutrition while $17(34 \%)$ were having average knowledge malnutrition followed by $6(10 \%)$ were in category of very good and no were having below average.

TABLE 3: Mean, Median and Standard Deviation of knowledge of Primary School Teachers regarding malnutrition among children $\mathbf{N}=\mathbf{5 0}$

\begin{tabular}{llcc}
\hline \multicolumn{1}{c}{ Test } & Mean & Median & SD \\
\hline $\begin{array}{l}\text { Knowledge } \\
\text { scores }\end{array}$ & 19 & $\mathbf{2 0}$ & $\mathbf{2 . 2}$ \\
\hline
\end{tabular}

Maximum possible score:30

The data in table 3 revealed that the mean of the knowledge of Primary school teachers regarding malnutrition was 19. The findings also revealed that the median and standard deviation of knowledge score were 20 and 2.2 respectively.

TABLE 4: Mean and mean percentage of the knowledge area of structured knowledge questionnaire of primary school teachers. $\mathbf{N}=\mathbf{5 0}$

\begin{tabular}{|c|c|c|c|c|}
\hline \multirow{7}{*}{$\begin{array}{l}\text { given } \\
\text { table } 4\end{array}$} & Knowledge Areas & No. Of Questions & Mean score & Mean\% score \\
\hline & Introduction \& Definition & 07 & 4.84 & 69 \\
\hline & Causes & 01 & 0.72 & 72 \\
\hline & Risk factors & 04 & 2.04 & 51 \\
\hline & Sign and symptoms & 08 & 5.86 & 73 \\
\hline & Treatment & 04 & 2.46 & 61 \\
\hline & Prevention & 06 & 3.54 & 59 \\
\hline
\end{tabular}

revealed that the structured knowledge questions categorized into 6 knowledge area i.e. introduction and definition of malnutrition, causes of malnutrition, risk factors of malnutrition, sign and symptoms of malnutrition, treatment of malnutrition and prevention of malnutrition.

Primary school teachers had good knowledge in the area of sign and symptoms of malnutrition(73\%), causes of malnutrition(72\%), introduction and definition of malnutrition(69\%)and treatment of malnutrition(61\%), while adequate knowledge in prevention of malnutrition $(59 \%)$ and risk factors of malnutrition(51\%).

The computed chi square value of 7.95 revealed that there was significant relationship between level of knowledge and educational status at 0.05 level of significance. This indicated that level of knowledge of primary school teachers was independent of their age, gender, marital status, total year of teaching experience and have you ever come across child with malnutrition.

\section{IMPLICATIONS}

The study was conducted to assess the level of knowledge of primary school teachers regarding malnutrition among children at selected primary schools of Ambala Haryana.

Nursing Practice: Malnutrition includes education of primary school teachers about school going children health, reducing incidence practice of disease and proper management regarding malnutrition problem.

Nursing education: Nursing education should focus its attention on practice, from curative to the preventive care by using extensive health education in their nursing care. The student be encouraged to take innovative, interesting health education activities in health promotion. It should in corporate newer approaches and strategies in the curriculum.

Nursing Administration: It is essential for nursing administrator to facilitate activities to improve knowledge and practice of public towards significant health problems. The administration should enable the nursing personal to develop newer skills through in- service education and continuing education.

Nursing research: Nursing personnel is being one of the important health care personnel providing primary health care have the challenging task of health promotion, implications for research include replicating study in other geographic areas.

\section{Acknowledgement:}

At very outset, I would like to thank almighty for his presence. My sincere thanks goes to all participants of my study. lastly and most importantly I am grateful to everybody who was important to successful realization of thesis including my family who supports at every step of my life. 
ETHICAL CONSIDERATION: Ethical approval to conduct the study was obtained from Institutional Ethical Committee of M.M University, Mullana, Ambala, Haryana. Written informed consent was obtained from the study subjects regarding their willingness to participate in the research project.

CONFLICT OF INTEREST: There is no conflict of interest.

FUNDING SOURCE: self financed.

\section{REFERENCE:}

[1]. K Park.Textbook Of Preventive And Social Medicine,20 ${ }^{\text {th }}$ Edition Jabalpur : Banarsidas Bhanot publishers;2005 p 225

[2]. Sudheer K A textbook of nutrition , $11^{\text {th }}$ edition India Florence publ Ghosh S, Shah D Nutritional problems . Journal of Indian Pediatrics 2004;15-16

[3]. Ghosh S , Shah D Nutritional problems . Journal of Indian Pediatrics 2004;15-16. ishers;2010 p 32

[4]. Surabi SM. Malnutrition among children. Times of India 2004;249(7):92-7

[5]. Faber \& Winhold 2007:393; Lapidaries 2005:119). 